\title{
Demographic costs of masting for a Bornean rain forest tree species, Scaphium macropodum
}

\author{
Toshihiro Yamada $^{1 *}$, Eizi Suzuki ${ }^{2}$, Pieter A. Zuidema ${ }^{3}$ \\ 'Graduate School of Integrated Arts and Sciences, Hiroshima University, Higashi-Hiroshima, 739-8521, Japan \\ ${ }^{2}$ Graduate School of Science and Engineering, Kagoshima University, Kagoshima, 890-0065, Japan \\ ${ }^{3}$ Centre for Ecosystem Studies, Wageningen University, PO Box 47, 6700 AA Wageningen, The Netherlands \\ *Corresponding author: yamada07@hiroshima-u.ac.jp
}

\begin{abstract}
Masting - the synchronous production of large fruit crops of conspecific trees among years - is a life history strategy in SE Asian tree species. While the reproductive biology of masting is relatively well described, the demographic consequences of masting are poorly understood. Theoretically, irregular production of seeds (masting) is less advantageous than annual fruiting for population growth, even if seed production is proportional to fruiting interval. This is related to the mortality risk between fruiting events, which needs to be compensated by a disproportional increase in seed production in order to maintain the same population growth. To assess the demographic costs of masting for Scaphium macropodum displaying masting behavior, population dynamics of this species in a tropical rain forest in West Kalimantan, Indonesia was studied using a stochastic matrix model. Our stochastic matrix model analyses of different fruiting frequencies revealed a long-term population growth rate of 1.002 for a situation in which fruiting occurs every 16 years. The average masting frequency in the region is higher than this frequency, and we therefore expect populations of our study species to be sustained. Stochastic elasticity analysis suggested that population growth rate was rather insensitive to the level and/or frequency of seed production while it was highly sensitive to adult survival. Stochastic population growth rates were barely reduced when fruiting intervals were prolonged and a proportional increase in seed output was simulated. Hence, if irregular reproduction is combined with increased seed output during fruiting events, the demographic costs of masting may be fully compensated.
\end{abstract}

Key words: elasticity, emergent tree, population growth rate, matrix, stochastic elasticity

\section{INTRODUCTION}

Masting occurs in trees in SE Asian tropical forests (Appanah 1993, Chan and Appanah 1980, Yasuda et al. 1999, Numata et al. 2003) as well as those in other biomes (Sork 1993, Sork et al. 1993). Several hypotheses concerning the adaptive significance of masting have been proposed in ecological and evolutionary studies (Herrera et al. 1998, Kelly 1994, Norton and Kelly 1988). Scientists suggested that masting reduces the impact of seed predators (frugivorous mammals) on seed survival by keeping their populations low during periods between mast years (Curran and Webb 2000, Janzen 1974, Silvertown 1980). This idea is often called the "predator satiation hypothesis'. The hypothesis has been supported by field observations for many plant species (Crawley and Long 1995, Kelly and Sullivan 1997, Koenig et al. 1994, Shibata et al. 1998, Shibata et al. 2002, Sork 1993). Another hypothesis explaining the evolution of masting behavior is 'pollination efficiency hypothesis' (Smith et al. 1990). According to the hypothesis, masting enhances crossbreeding among trees and disproportionately increases fertilization and seed set (Smith et al. 1990). This hypothesis has explained mainly masting in windpollinated species (Allison 1990, Kelly et al. 2001, Kon et al. 2005). Since most of trees in SE Asian tropical forests are pollinated by animals (Appanah and Chan 1981, Bawa 1998, Momose et al. 1998), the application of this hypothesis to the tropical forest trees has been limited. However on the other hand, there was a report showing the attraction of reproductive synchrony for pollinators and increased pollination success for a neotropical shrub species (Augspurger 1981). Finally, Inoue (1997) successfully expanded this hypothesis to tropical forest trees by introducing the idea that mass flowering increases pollinator activity through immigration and population growth and enhances crossbreeding among trees. This is called as "promotion of pollination 
hypothesis' (Sakai 2002).

The adaptive significance of masting has been focused on by many scientists as stated above. However inevitably, the irregular production of seeds (masting) induces "demographic costs" to masting tree species (Visser et al. 2011). First, let us assume that the number of seeds produced by a tree in one masting event equal to the amount that a tree would produce when fruiting every year and independent of the length of the masting interval (non-fruiting years). This idea may be supported by the finding that a dipterocarp species used current photosynthates as a carbon source during fruit development (Ichie et al. 2005). In this case, masting reduces total amount of seeds produced during the life time of a tree, because it reduces life time fruiting opportunities. Thus, long masting intervals may cause population shrinkage, a strong demographic cost. Perhaps the assumption of equal fruit production irrespective of the masting interval is not realistic, and the seed production during a masting event is proportional to the length of masting interval (Isagi et al. 1997). Trees could accomplish this by storing reserves for future masting events. It was suggested that North American deciduous oaks displaying masting behavior must store resources during some years to produce a mast crop (Soak et al. 1993). But also in that case, masting is less advantage compared to annual fruiting, as mature trees run the risk of dying before the next masting event. Clearly, this risk increases with increasing masting interval. Why do some tree species have masting strategy though they inevitably take the risk? What extent does the masting entail the risk?

Due to the difficulty of observing a sporadic masting event in tropical trees, there is a scarcity of information of masting, and this limits our understanding of the demographic consequences of masting. In this study we monitored growth, mortality, and recruitment of Scaphium macropodum Miq. Beumee ex Heyne, a tropical emergent tree having masting behavior. We were fortunate to encounter a masting of this species in 1993 and could monitor seed production and seedling fate during the following years. With these data, we describe the population dynamics of this species using transition matrix model (Caswell 2001). Especially, we discuss to what extent irregular fruiting (masting) entails demographic cost (risk) for the population compared to annual fruiting by answering the following two questions. (1) How sensitive is population growth rate $(\lambda)$ to masting interval under the assumption that seed output is proportional to the masting interval? (2) Which vital rates are the most important to sustain populations of this masting species, given the temporal stochasticity in fruiting? To answer these questions, we calculate stochastic $\lambda$ (Caswell 2001) for different masting intervals and different levels of seed production. We also conduct stochastic elasticity analysis (Tuljapurkar et al. 2003).

\section{MATERIALS AND METHODS}

\section{Study site and species}

The study was performed in a tropical rain forest on Mt. Berui, West Kalimantan, Indonesia. The location of the forest is $0^{\circ} 45^{\prime} \mathrm{N}$ and $110^{\circ} 6^{\prime} \mathrm{E}$. The forest is situated on undulating hilly lands ranging in elevation from ca. 200 to $600 \mathrm{~m}$ above sea level (asl), and covers an area of ca. $1,100 \mathrm{ha}$. The average annual rainfall is $4,265 \mathrm{~mm}$ at Serimbu, the nearest village from Mt. Berui $(50 \mathrm{~m}$ asl and about $2.5 \mathrm{~km}$ north of the forest) and the average monthly rainfall never falls below $250 \mathrm{~mm}$. Further details of the forests such as vegetation, soil, and topography were described in Yamada and Suzuki $(1996,1997)$ and Kohyama et al. (2003).

Scaphium macropodum is a common emergent tree of the tropical rain forests of Malaya, Indochina, Sumatra, and Borneo (Kochummen 1972). It is a shade-tolerant species whose saplings can be found under the closed canopies (Yamada and Suzuki 1997). Trees lower than ca. $12 \mathrm{~m}$ in height have no branches and put their leaves on the terminal of the monoaxial stem (Yamada and Suzuki 1996). Their monoaxial growth habit allows us to measure stem height accurately. The tree produces wind-dispersed fruits with a boat-shaped wing that is derived from a dehiscing follicle. All fruits are one-seeded. The seeds of S. macropodum do not have dormancy and germinate soon after dispersal. The average length of the wings and fresh mass of the seeds were $16.6 \mathrm{~cm}(\mathrm{n}=13, \mathrm{sd}=1.9)$ and $2.21 \mathrm{~g}(\mathrm{n}=13, \mathrm{sd}=0.53)$, respectively (Yamada and Suzuki 1997). The seed is ellipsoid and the length of major axis was $2.64 \mathrm{~cm}(\mathrm{n}=13, \mathrm{sd}=0.14)$. The seeds are eaten by monkeys (Kochummen 1972).

\section{Field methods}

Two permanent plots of 1 ha $(100 \mathrm{~m} \times 100 \mathrm{~m})$, S- 1 and $\mathrm{S}-2$, were established on a gentle ridge running east-west at about $250 \mathrm{~m}$ asl. The plots were about $500 \mathrm{~m}$ apart . All trees larger than $4.8 \mathrm{~cm}$ in $\mathrm{dbh}$ (diameter at the breast 
height) were identified, tagged, mapped and measured by $\mathrm{dbh}$ in September 1992. They were measured again by $\mathrm{dbh}$ in October 1995. The tallest trees in S-1 and S-2 attained heights of $70 \mathrm{~m}$ and $60 \mathrm{~m}$, respectively. The total BA (basal area) was $44.7 \mathrm{~m}^{2} \mathrm{ha}^{-1}$ in S-1 and $42.6 \mathrm{~m}^{2} \mathrm{ha}^{-1}$ in S-2. Scaphium macropodum occupied $1.18 \%$ of total BA in S-1 and $0.64 \%$ in S-2. 285 and 325 tree species were recorded in S-1 and S-2, respectively. The plots were dominated by dipterocarp trees: Dryobalanops beccarii Dyer and many Shorea species were the most dominant species. The tall trees such genera as Scaphium, Gironniera, etc., made up the emergent layer with the dipterocarp trees. A large number of species belonging to Euphorbiaceae, Meliaceae, and many other families formed the main continuous canopy.

We mapped all $S$. macropodum trees $\leq 4.8 \mathrm{~cm}$ in $\mathrm{dbh}$ and measured their heights in S-1 and S-2 in September 1992. The spatial distribution of this species in the plots has been reported in Yamada and Suzuki (1997). We measured again their tree height in October 1995. In August 1993, S. macropodum in the forest fruited. Many dipterocarp trees such as $D$. beccarii and non-dipterocarp tree such as Elateriospermum tapos Blume also took part in this masting event (Simbolon et al. 2000). During our research period from 1992 to 1995, no Scaphium tree in the plots fruited in the other years. Scaphium trees in Sarawak flowered only in the general flowering period (Sakai et al. 1999). In 1993, we laid out a belt-transect of 4 $\mathrm{m} \times 100 \mathrm{~m}$ in S-2 to measure the distribution of fallen fruits and dynamics of seedlings (Yamada and Suzuki
1997). The belt transect included one fruiting $S$. macropodum individual of $48.1 \mathrm{~cm} \mathrm{dbh}$. There was another fruiting tree outside the belt transect, but it produced few fruits. All fruits in the belt-transect seemed to be dispersed from this tree and they were labeled with plastic number tapes and mapped on 30 August 1993 when all fruits on the tree had been dispersed. Position of the belt transect as well as mature $S$. macropodum trees in the plots are shown in Yamada and Suzuki (1997). Seeds germinated soon after dispersal (Yamada and Suzuki 1997) and no seeds were found at the next census in September 1993. Height of all seedlings was measured on October 10, 1994, and October 7, 1995.

\section{Vital rates of Scaphium macropodum}

Growth, mortality and fecundity of Scaphium macropodum were analyzed separately for 15 life historical stages (Table 1). Since sample size of Scaphium macropodum in Mt Berui was not enough large to analyze vital rates, we additionally used data acquired from the Pasoh Forest Reserve (mortality) and the Lambir Hills National Park (growth rate), Malaysia. These forests are typical dipterocarp forests without severe disturbance history with similar forest physiognomy to each other. The difference in mortality rate of $S$. macropodum between the Lambir forest $\left(0.991 \% \mathrm{y}^{\mathrm{r}-1}\right)$ and the Pasoh forest $\left(0.990 \% \mathrm{yr}^{-1}\right)$ was small and not significant (Fisher's exact test for count data, $\mathrm{P}=0.90)$, suggesting that this vital rate is similar in both sites.

Table 1. Size classes used in this study to project population dynamics of Scaphium macropodum in a West Kalimantan tropical rain forest

\begin{tabular}{|c|c|c|c|}
\hline & Size class & Criteria & No. of observed individuals in 1992 \\
\hline 1 & seed & seed and seedlings during one year after dispersal & $1331 \neq$ \\
\hline 2 & seedling & height $(\mathrm{h}) \leq 50 \mathrm{~cm}$ & 207 \\
\hline 3 & sapling-1 & $50 \mathrm{~cm}<\mathrm{h} \leq 100 \mathrm{~cm}$ & 130 \\
\hline 4 & sapling-2 & $100 \mathrm{~cm}<\mathrm{h} \leq 250 \mathrm{~cm}$ & 100 \\
\hline 5 & pole-1 & $250 \mathrm{~cm}<\mathrm{h} \leq 785(\approx 5 \mathrm{~cm}$ in $\mathrm{dbh})$ & 49 \\
\hline 6 & pole-2 & $5 \mathrm{~cm}<\mathrm{dbh} \leq 10 \mathrm{~cm}$ & 13 \\
\hline 7 & premature-1 & $10 \mathrm{~cm}<\mathrm{dbh} \leq 15 \mathrm{~cm}$ & 7 \\
\hline 8 & premature-2 & $15 \mathrm{~cm}<\mathrm{dbh} \leq 20 \mathrm{~cm}$ & 3 \\
\hline 9 & mature-1 & $20 \mathrm{~cm}<\mathrm{dbh} \leq 25 \mathrm{~cm}$ & 0 \\
\hline 10 & mature-2 & $25 \mathrm{~cm}<\mathrm{dbh} \leq 30 \mathrm{~cm}$ & 0 \\
\hline 11 & mature-3 & $30 \mathrm{~cm}<\mathrm{dbh} \leq 35 \mathrm{~cm}$ & 1 \\
\hline 12 & mature-4 & $35 \mathrm{~cm}<\mathrm{dbh} \leq 40 \mathrm{~cm}$ & 0 \\
\hline 13 & mature-5 & $40 \mathrm{~cm}<\mathrm{dbh} \leq 45 \mathrm{~cm}$ & 1 \\
\hline 14 & mature-6 & $45 \mathrm{~cm}<\mathrm{dbh} \leq 50 \mathrm{~cm}$ & 2 \\
\hline 15 & mature-7 & $50 \mathrm{~cm}<\mathrm{dbh}$ & 0 \\
\hline
\end{tabular}


Annual mortality rates $(m)$ were calculated following Sheil et al. (1995). Annual mortality rates for size classes of seeds and seedlings were calculated based on the data of the belt-transect census from 1993 to 1995 . Annual mortality rates for sapling-1, sapling- 2 and pole-1 were based on the census data from 1992 to 1995 of the two, 1-ha plots. Mortality for trees larger than $5 \mathrm{~cm}$ in $\mathrm{dbh}(\geq$ pole-2) was very rare and only one tree in the plots died during our study period. We therefore obtained annual mortality rates of this species ( $>5 \mathrm{~cm}$ in $\mathrm{dbh}$ ) from the 50 ha plot data in the Pasoh Forest Reserve, Malaysia for the period 1985-1995 $(n=370)$. We assumed a constant mortality rate among trees larger than $5 \mathrm{~cm}$ in $\mathrm{dbh}$. The obtained mortality rate was c. $1 \% \mathrm{yr}^{-1}$, which is almost identical to those for congeneric species, Scaphium borneense in the Lambir Hills National Park (Yamada et al. 2007)

We calculated height growth rate for size classes $\leq$ pole-1, and calculated dbh growth rate for size classes $>$ pole-1. Annual growth was determined for every tree as the slope of a linear regression of two measurement of height or dbh against time. The annual height growth rates were calculated for seedling based on data of the belt transect census, and those for the sapling-1, sapling-2 and pole-1 were calculated based on the plots census data. In order to increase sample size for the analysis of annual dbh growth, we added dbh growth data of 22 additional trees (1992-1997) from the 52-plot in Lambir Hills National Park, Sarawak. The size-dependent growth pattern and variation of these two datasets were visually comparable.

The number of seeds produced by a mature tree was estimated based on the data of the belt-transect. Seed density $\left(\mathrm{m}^{-2} ; Y\right)$ were well fitted by an exponential function of the distance from the mother tree $(\mathrm{m} ; X)\left(R^{2}=0.97\right)$ :

$$
Y=5.3012 e^{-0.079 X} \text {. }
$$

The volume of the cone that is produced when rotating the equation (1) around the $Y$-axis represents the total number of seeds produced by the tree. We calculated this volume to estimate total seed production by this tree. Since the equation (1) was fitted for $X<52 \mathrm{~m}$, it cannot be applied for $X>52 \mathrm{~m}$. Therefore, we assumed that all seeds dispersed at $<52 \mathrm{~m}$ from the fruiting tree. Our estimate is that a total of 4,860 seeds was produced by the fruiting tree during the 1993 masting event. In 1993, we observed 19 fruiting $S$. macropodum trees in Mt. Berui and this tree was seemed to have a medium crop among them.

\section{Parameterization of matrix models}

Life historical stage classified projection matrices were used to project the size and structure of populations in time (Caswell 2001). Matrix models have the basic form $\mathrm{n}(t+1)=A \mathrm{n}(t)$, where $A$ is a square matrix with transitions among size classes during one time step $(=1$ year in this study), and $n$ is the population vector containing densities of individuals in life historical stages. The dominant eigenvalue $(\lambda)$ of matrix $A$ is equivalent to the population growth rate (hereafter referred to as deterministic $\lambda$ ). The stable population structure is the right eigenvector (hereafter referred to as deterministic size structure). We measured the distance between the deterministic size structure generated by the matrix and observed size structure by Keyfitz's $\Delta$ (Caswell 2001) to see the similarity between the matrix generated stable population structure and observed one in the plots in 1992. Note that size structures did not included a seed category, as seeds germinate within one year (Caswell 2001).

In our matrix model, elements $a_{i j}$ of transition matrix $A$ can be grouped into those representing stasis $\left(P_{j}\right.$; the probability of surviving and remaining in size-class $j$ over the time interval), progression $\left(G_{i j}\right.$; the probability of surviving and growing from size-class $j$ to $i, i=j+1$ ), and fecundity $\left(F_{j}\right.$; the number of sexual offspring produced by an individual in stage $j$ ). Matrix elements were built from underlying vital rates, which are survival $(\sigma)$, annual growth $(g)$, and reproduction output $(f)$, to which they are related by $G_{i j}=\sigma_{j} \times g_{j} / c_{j}$ (of which $c_{j}$ is category width), $P_{j}=\sigma_{j}-G_{i j}$, and $F_{j}=\sigma_{j} \times f_{j}$. Although there is a scarcity of information of this species's reproductive ecology, many tropical trees showed a size dependency of reproduction (Zuidema and Boot 2002; Naito et al. 2008; Chien et al. 2008). The majority of $S$. macropodum trees larger than $20 \mathrm{~cm}$ in $\mathrm{dbh}$ fruited in 1993 on Mt. Berui (T. Yamada, unpublished data). Then we assumed that reproduction starts when trees reached $20 \mathrm{~cm} \mathrm{dbh}$, and that the production of seed increases linearly with $\mathrm{dbh}$, and reaches $100 \%$ (= 4,860 seeds) when trees attain $45 \mathrm{~cm} \mathrm{dbh}$.

We applied time-varying models (Caswell 2001, Tuljapurkar et al. 2003, Zuidema and Boot 2002) to obtain stochastic population growth rates for populations with different time interval between consecutive mast fruiting events $(p)$. First we constructed two matrices; one for a fruiting year $\left(A_{f}\right)$ and the other for non-fruiting year $\left(A_{\text {non } f}\right) . A_{f}$ and $A_{\text {nonf } f}$ only differ in the fecundity element $\left(F_{j}\right)$, which is 0 in the latter. As fruiting years occur randomly 
in time, a 'time-homogeneous stochastic model' was applied (sensu Caswell 2001). This model chooses one of the two matrices randomly at each time step for a long period of time. Subsequently, the overall average growth rate over this long period is calculated. Although yeartypes are chosen at random in the model, the probability of occurrence of each of the year-types is fixed depending on $p$. In a model assuming fruiting every year $(p=1)$, the probability of occurrence of masting is 1.0 , though in another model assuming fruiting every two years $(p=2)$, the probability is 0.5 . At each time step, the instantaneous population growth, $\lambda(t)$, is calculated as (Silva et al. 1991):

$$
\log \lambda(t)=\log N(t+1)-\log N(\mathrm{t})
$$

where $N$ is the population size (the sum of the population vector). These instantaneous estimates can then be averaged over a long time interval (in this study, $T=$ 100,000 years and discarded the first 1000 years; Silva et al. 1991) using:

$$
\log \lambda_{\mathrm{S}}=\frac{1}{(T-1)} \sum \log \lambda(t)
$$

Hereafter, the $\lambda_{\mathrm{s}}$ is referred to as stochastic $\lambda$.

Longer time interval between fruiting events $(p)$ may increase seed production in a fruiting event, as it allows trees to accumulate reserves for longer time. To take this effect into consideration, we calculated $\log \lambda_{\mathrm{s}}$ with seven levels of seed production $(m): 4,2,1,1 / 2,1 / 4,1 / 8$ and $1 / 16$ times the observed fecundity.

To quantify the importance of each matrix element to stochastic $\lambda\left(\lambda_{s}\right)$, we conducted elasticity analysis. Elasticity analysis considers the impact of a proportional change in a matrix element on proportional change in $\lambda$ (de Kroon et al. 1986). We performed numerically perturbation analysis for matrix elements to obtain elasticity values of each matrix element as follows (Caswell 2001, Tuljapurkar et al. 2003, Zuidema et al. 2010). First we numerically calculated $\lambda_{s}$ again by increasing $a_{i j}$ by $1 \%$. Then we calculated stochastic elasticity as,

$$
\text { elasticity }=\frac{\Delta \lambda_{s} / \lambda_{s}}{0.01},
$$

in which $\Delta \lambda_{\mathrm{s}}$ is the change in $\lambda_{\mathrm{s}}$ resulting from the $1 \%$ increase in $a_{i j}$. The stochastic elasticity values may change with change in $p$ and $m$. So we calculated the stochastic elasticity values for models with the combination of $p=1$ to 16 years and $m=4,2,1,1 / 2,1 / 4,1 / 8$ and $1 / 16$. Stochastic size structure was also calculated by calculating size structure for each year of 100,000-year projections of population and averaging them.

\section{RESULTS}

\section{Vital rates}

Survival of seedling during the first year after dispersal was very low: only $8.1 \%$ of the seeds survived. There was no visual evidence (ex., a bite scar, etc) of seed or seedling predation by mammals. Seedlings also showed high mortality; $53.7 \%$ year $^{-1}$ in the second year after dispersal. Mortality rates strongly dropped at larger size classes, being always lower than $4 \%$ (those for sapling-1, sapling-2, and pole- 1 were $3.2 \%, 1.5 \%$ and $1.5 \%$, respectively). According to the Pasoh data, $S$. macropodum over $5 \mathrm{~cm}$ in dbh showed only ca. $1 \%$ annual mortality (35 out of 370 trees died in a period of 5 years).

Seedling height growth rates of this species were very high; maximum growth rates often amounted over $40 \mathrm{~cm}$ per year (Fig. 1). Height growth rates were highly variable within a size class and did not distribute normally in each size class with many slow growers and a few fast growers. Because of this non-normality, we used a median value of height growth rates rather than mean value for the parameterization of the transition matrix (i.e., $g_{j}$ for size classes $\leq$ pole-1). Note that this might ignore fast growers in gaps and thus underestimate $g_{j}$. Diameter growth of trees was shown in Fig. 2. Diameter growth increased from low value for small trees, peaked at ca 25 $\mathrm{cm} \mathrm{dbh}$, and was gradually reduced at higher $\mathrm{dbh}$ values.

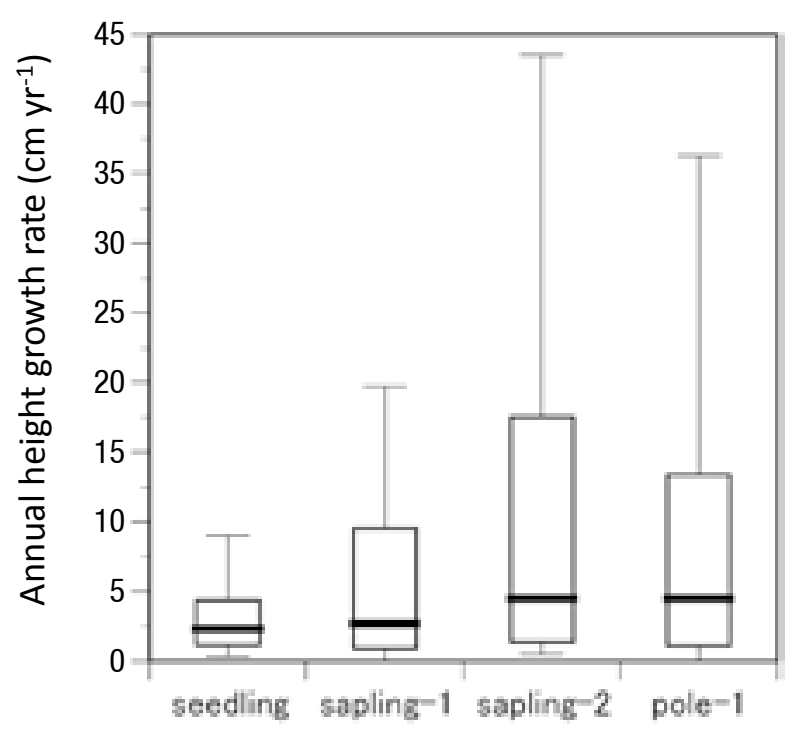

Fig. 1. Height growth rates for size classes of seedling, sapling-1, sapling-2, and pole-1 for Scaphium macropodum in a West Kalimantan tropical rain forest. Horizontal bars, boxes, and vertical lines denote median values, interquartile ranges, and $90 \%$ ranges, respectively. 


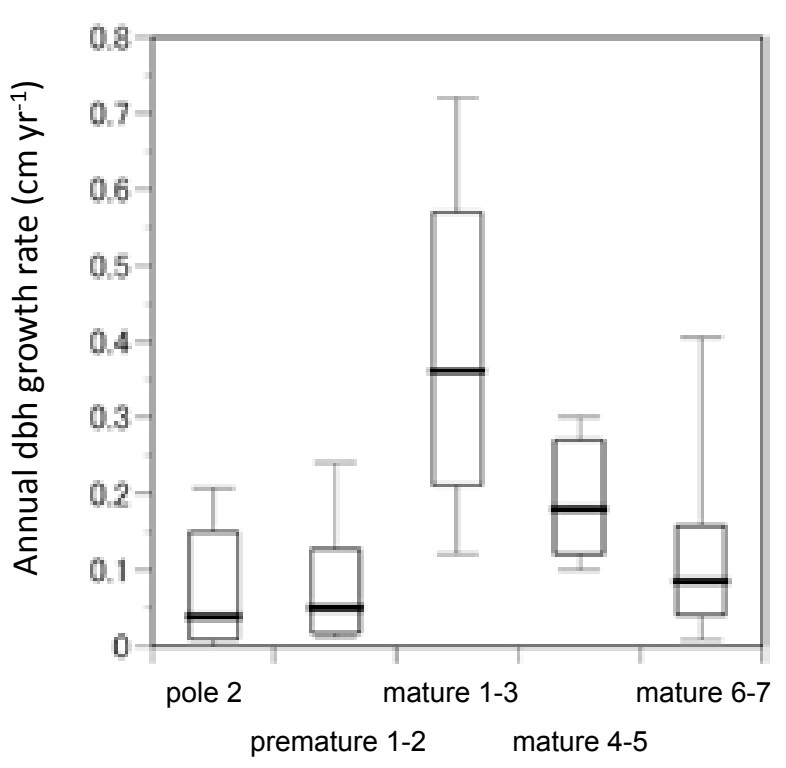

Fig. 2. Dbh growth rates for size classes $>$ pole-2 for Scaphium macropodum in a West Kalimantan tropical rain forest. Horizontal bars, boxes, and vertical lines denote median values, interquartile ranges, and $90 \%$ ranges, respectively.
For the parameterization of the transition matrix, a median value of $\mathrm{dbh}$ growth rates was used.

\section{Matrix analysis}

The deterministic structure that was produced by the transition matrix with $p=1\left(A_{f}\right)$ resembled the observed size structure well (Fig. 3). The Keyfitz's $\Delta$ between the two size distributions was only 0.105 , indicating that differences between the two size structures were very small, in spite of the very small dataset of our study as well as the time-varying character of the regeneration in this species. The stochastic size structures showed a large variance in relative frequency within a size class in each case of the time-varying matrix models. This variance was especially large in for small size categories. The relative proportion of seedlings in the stochastic stage structure was low for stochastic models with high $p$.

Deterministic population growth rate $(\lambda)$ for a situation with annual fruiting $\left(A_{f}\right)$ was 1.012 . We also calculated the hypothetical case of a population that is not
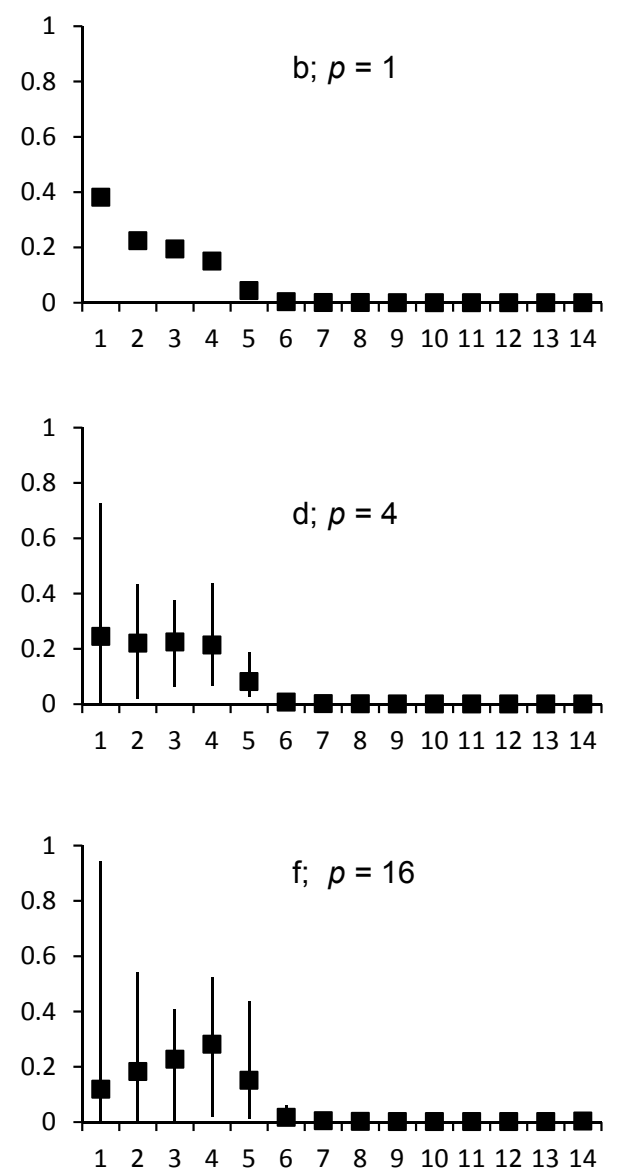

Size class

Fig. 3. Observed size structure in 1992 (triangle) and 1995 (circle) (a) and size structure generated by matrix with different interval of fruiting (b to f) for Scaphium macropodum in a West Kalimantan tropical rain forest. Shown are mean (square) and sd (bar) values of relative frequency among 100,000-year population projections. Size classes are shown in Table 1. 
reproducing at all: for this deterministic model $\left(A_{\text {non- } f}\right) \lambda$ was 0.990 . This population growth rate purely based on the growth and survival of individuals in the population, without any recruitment.

Population growth rates decrease as fruiting intervals increase, if $m$ was kept constant (Fig. 4). For example, when we focus on the model with the same magnitude of seed production as the observed value for $1993(m=1)$, the value of $\lambda_{\mathrm{s}}$ decreased from 1.012 to 1.002 when $p$ increased from 1 to 16 year. This analysis suggests that our study species requires fruiting years every 16 years in order to sustain populations, when assuming that trees seed production during fruiting is similar to that observed in 1993.

As expected, $\lambda_{\mathrm{s}}$ decreased with fruiting intervals even in the case that seed production during a fruiting event is proportional to the length of fruiting interval (Fig. 4). But this decrease was slow, and as a result, the difference in the value of $\lambda_{\mathrm{s}}$ among models with various fruiting intervals $(p)$ was subtle. For example, $\lambda_{\mathrm{s}}$ for the model with $m=1 / 4$ and $p=1$, that with $m=1 / 2$ and $p=2$, that with $m=1$ and $p=4$, that with $m=2$ and $p=8$ and that with $m=4$ and $p=16$ were very similar: 1.006614 , $1.006613,1.006612,1.006610$, and 1.00603, respectively. This implies that the irregularity of fruit production

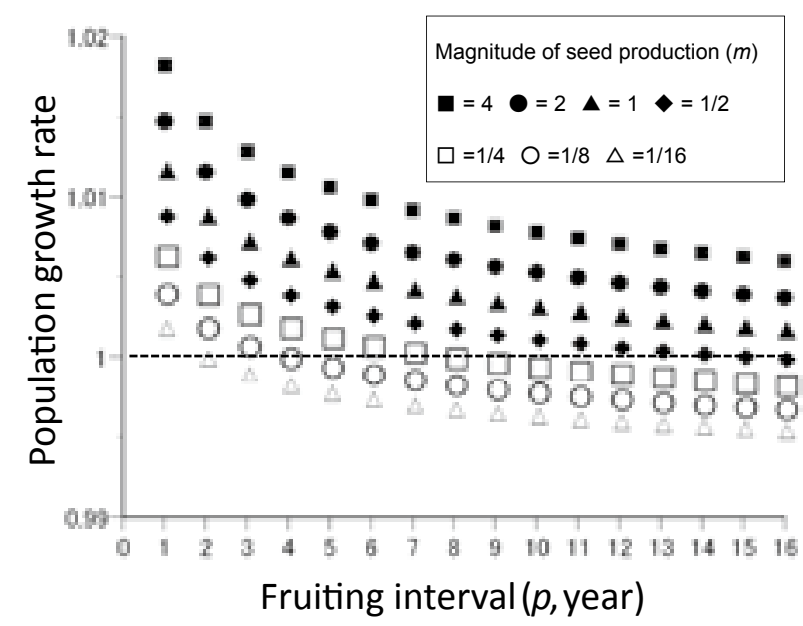

Fig. 4. Relationship between population growth rate $\left(\lambda_{\mathrm{s}}\right)$ and fruiting interval (year) for Scaphium macropodum in a West Kalimantan tropical rain forest. A dotted line denotes $\lambda_{\mathrm{s}}=1.0$. Population growth rates were calculated for various time varying models with different masting interval $(p)$ and magnitude of seed production $(m)$. Fruiting interval of 1 , for example, stands for that trees fruit every year, whereas $p$ of 5 stands for that trees fruit once every five years. Magnitude of seed production of 1, for example, stands for that trees produce the same number of seed to observed number in a fruiting event in 1993, while $m$ of 4 stands for that trees produce four times as large number as observed number of seed produced in the fruiting event in 1993. hardly affects population growth rate as long as seed production during fruiting events is proportional to the length of fruiting interval.

Figure 5 shows the stochastic elasticity values for $\lambda_{\mathrm{s}}$ for the model with $p=1.0$ and $m=1.0\left(A_{\mathrm{f}}\right)$. Stochastic elasticity analysis showed that stasis elements (those elements that contain the probability that individuals stay in the same category) were the most important for $\lambda_{\mathrm{s}}$, followed by progression elements. Fecundity elements were much less important (lower elasticity) than progression and stasis elements. This trend of stochastic elasticity values over matrix elements was almost identical among models with different $p$ (Fig. 6) as well as $m$ (results now shown). But with increasing $p$, stochastic

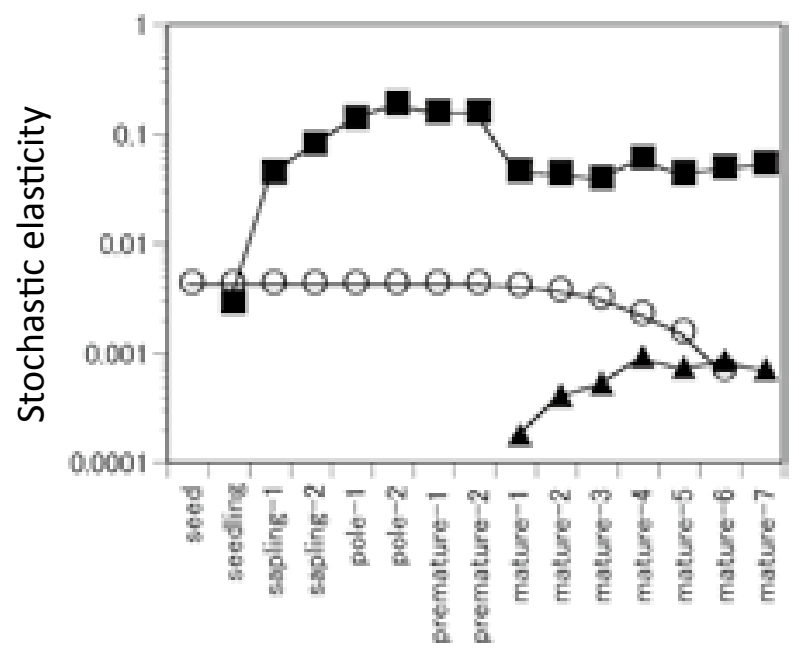

Fig. 5. Stochastic elasticity values for $\lambda_{\mathrm{s}}$ for Scaphium macropodum in a West Kalimantan tropical rain forest. Values are calculated using a model with $p$ of 1.0 and $m$ of 1.0. Elasticity valves for stasis (a), progression $(\circ)$ and fecundity $(\boldsymbol{\Delta})$ elements of every size class are shown. Size classes are shown in Table 1.

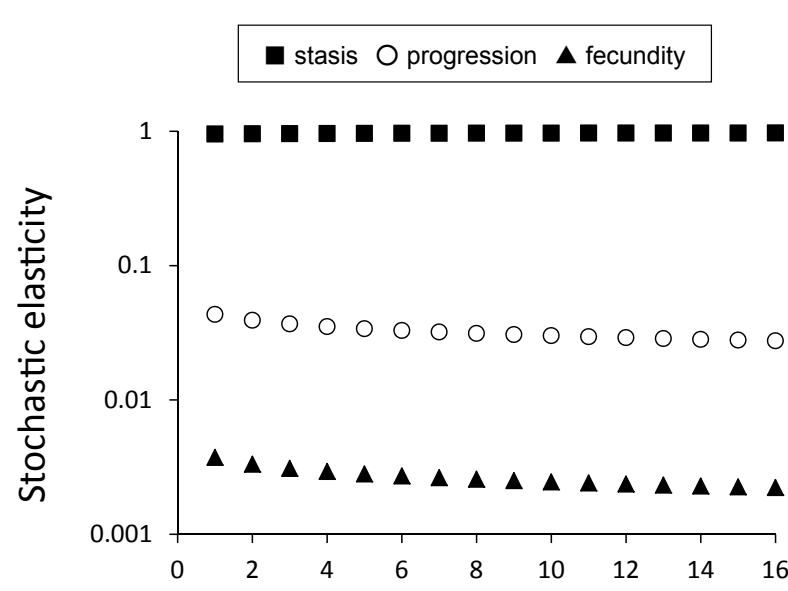

Fruiting interval ( $p$, year)

Fig. 6. Change in stochastic elasticity values for stasis (a), progression $(\circ)$ and fecundity $(\boldsymbol{\Delta})$ elements with increasing in masting interval $(p)$. Shown are sum of elasticity values over all size classes. 
elasticity values for progression and fecundity elements decreased (Fig. 6).

In our all time-varying models, stochastic elasticity of progression elements from seed to seedling (= seedling survival for one year after dispersal) was identical to the elasticity of fecundity elements. This means that a given percent increase in fecundity has the same effect on $\lambda_{\mathrm{s}}$ as the same percent increase in seedling survival for one year after dispersal.

\section{DISCUSSION}

\section{Population growth rate and masting interval}

As we had predicted, stochastic population growth rates $\left(\lambda_{\mathrm{s}}\right)$ of our study species decreased with the length of the fruiting interval (Fig. 4). This happened under the assumption that the amount of seed produced in a fruiting event keeps constant irrespective of fruiting interval. Therefore under this assumption, masting (irregular production of seed large crops) is disadvantageous for sustaining population if compared with annual fruiting. However even in that case, the rate of decrease in $\lambda_{\mathrm{s}}$ with increasing fruiting interval was quite low. Consequently, the value of $\lambda_{\mathrm{s}}$ was still over unity even in the case that fruiting frequency was 16 years. Hence, if seed production during fruiting events is similar to that observed in our study, populations of Scaphium macropodum are projected to survive if fruiting intervals are $<16$ years. In our study site, Scaphium trees fruited only once in three years from 1992 to 1995. Similarly, congeneric tree species in Jinghong fruited once in 3 to 4 years (Jinhua et al. 1998). Although very long-term observation is apparently necessary to clarify the actual fruiting frequency of this species, these hinted that the fruiting frequency may be 3 to 4 years. To the extent that fruiting frequency is 3 to 4 years, $S$. macropodum may be able to sustain its population. Fruiting frequency can be estimated by another way. Scaphium in Sarawak took part in general flowering when many dipterocarp trees flowered (Sakai et al. 1999). Masting interval for dipterocarp trees in the region was calculated as 5.2 year (for 1950 to 1984 , Ashton et al. 1988). Similarly, Burgess (1972) described that masting occurred every 2 to 6 years in Peninsular Malaysia. Assuming that S. macropodum has similar fruiting frequency with above reports, we can again cautiously conclude that $S$. macropodum would be able to sustain population in SE Asian tropical rain forests under the current frequency of masting events.

But we need to note that in Borneo, dry episodes of several months with extremely low precipitation occur on a supra-annual base, as an effect of ENSO (The El NiñoSouthern Oscillation) (Ropelewski and Halpert 1996, Walsh and Newbery 1999, Walsh 1996). In this dry spells, mortality of trees increased due to drought (Nakagawa et al. 2000), insect outbreak (Bebber et al. 2002) and forest fires (Van Nieuwstadt and Shiel 2005). During our research period from 1992 to 1995, the forest did not experience such severe drought. It is very likely that in dry years the mortality of $S$. macropodum increases. Therefore our conclusion that population of $S$. macropodum in SE Asian tropical rain forests can be sustained may be on the optimistic side. Information on the impact of severe droughts on survival and growth is required to assess the effect of the climatic fluctuations on $\lambda_{\mathrm{s}}$.

Theoretically, the value of $\lambda_{\mathrm{s}}$ decreases with an increase in fruiting interval even in the case that the amount of seeds produced in a fruiting event increases proportionally with the length of masting interval. This decrease in population growth is due to the risk that reproductive trees die before the next fruiting event. Our analysis of $\lambda_{\mathrm{s}}$ indeed showed that $\lambda_{\mathrm{s}}$ value decreased with fruiting interval even in the case of the proportional increase in seed production to the length of fruiting interval (Fig. 4). But the difference in $\lambda_{\mathrm{s}}$ among the models with various fruiting intervals was very small. The fact that the decrease in $\lambda_{\mathrm{s}}$ with increasing masting interval was small, suggests that having long fruiting interval has little disadvantage to population growth rate compared with fruiting in every year, if tree increases amount of seeds proportionally to the non-fruiting years. Similar very low demographic costs of masting were shown for a SE Asian tropical dipterocarp tree (Visser et al. 2011).

\section{The most important vital rates for population growth}

Our perturbation analysis showed that fecundity contribruted little to $\lambda_{\mathrm{s}}$ compared to for stasis and progression. Therefore, for the maintenance of population, stasis (survival) and progression (growth) are much more important than fecundity. This distribution of stochastic elasticity values over transition types is commonly found for long lived woody species (Silvertown et al. 1992; Silvertown et al. 1993) and may explain the slow decreasing rate of $\lambda_{\mathrm{s}}$ with increasing fruiting interval. Low elasticity of fecundity suggests that the reduction of fecundity due to long fruiting interval does not strongly affect $\lambda_{\mathrm{s}}$. As stasis elements are of 
paramount importance for $\lambda_{\mathrm{s}}$, the high survival of large Scaphium macropodum individuals likely greatly contributed to keep $\lambda_{\mathrm{s}}$ above unity.

\section{Evaluating the fitness of masting}

The predator satiation hypothesis is the most frequently mentioned explanation of the evolution of masting behavior in SE Asian tropical forests. In this study, we have not been able to evaluate whether this hypothesis likely has played a role for our study species: we have not established that more seeds of the species can escape from seed predators during masting year than nonmasting year. There has been empirical support for this hypothesis in field studies. In West Kalimantan, Indonesia only a few percent of community seed production were destroyed by resident vertebrates during a mast event, although all monitored seed were destroyed during a minor mast event (Curran and Leighton 2000). In Peninsular Malaysia, only 11\% total Shorea seeds could survive during minor mast events, whereas $48 \%$ total seeds could do in a mast event (Sun et al. 2007). An important question that has not been answered in these studies is: What is the minimum required level of increase in seed and seedling survival to make masting a viable strategy. If seed production is reduced when changing from annual fruiting to masting, a small increase in seedling survival may not compensate for the demographic cost of decreased long-term seed production. Namely, both demographic costs and benefits of masting need assessing for the evaluation of the fitness consequence of masting behaviors (Visser et al. 2011). Our stochastic matrix analysis showed that elasticity of seedling survival for one year after dispersal was identical to that of fecundity elements (Fig. 5). Hence, if long-term seed production decreases by a given percentage for a masting species, seedling survival should increase by the same percentage in order to keep population growth rate at the same level. Finally we conclude that to assess the adaptive significance of masting and to verify the predator satiation hypothesis, we must know not only the increase in seedling survival inflicted by masting (i.e., demographic benefit), but also take into account the demographic costs related to masting.

ACKNOWLEDGEMENTS Drs. T. Okuda of Hiroshima University and T. Yamakura of Osaka City University kindly allowed using plot data of Pasoh Forest Reserve and Lambir Hills National Park. Indonesian Institute of Science (LIPI) kindly issued research permission (Izin
Penelitian No.: 6356/II/1992) and supported our study. This study was finically supported by International Scientific Research Program, No. 03041064 from the Japanese Ministry of Education, Culture, Sports, Science and Technology, Japan.

\section{REFERENCES}

Allison TD. 1990. Pollen production and plant density affect pollination and seed production in Taxus canadensis. Ecology 71:516-522.

Appanah S. 1993. Mass flowering of dipterocarp forests in the aseasonal tropics. Journal of Bioscience 18:457474.

Appanah S, Chan HT. 1981. Thrips: the pollinators of some dipterocarps. Malaysian Forester 44:234-252.

Ashton PS, Givnish TJ, Appanah S. 1988. Staggered flowering in the Dipterocarpaceae, new insights into floral induction and the evolution of mast fruiting in the aseasonal tropics. Tne American Naturalist 132:44-66.

Augspurger CK. 1981. Reproductive synchrony of a tropical shrub: experimental studies on effects of pollinators and seed predators on Hybanthus prunifolium (Violaceae). Ecology 62:775-788.

Bawa KS. 1998. Conservation of genetic resources in the Dipterocarpaceae. In: Appanah S, Turnbull JM. (eds) A review of dipterocarps taxonomy, ecology and silviculture. Center for International Forestry Research, Bogor. 45-55.

Bebber D, Brown N, Speight M. 2002. Drought and root herbivory in understorey Parashorea Kurz (Dipterocarpaceae) seedlings in Borneo. Journal of Tropical Ecology 18:795-804.

Burgess PF. 1972. Studies on the regeneration of the hill forests of the Malay Peninsula. Malaysian Forester 35:103-123.

Caswell H. 2001. Matrix Population Models. Sinauer Associates, Sunderland.

Chan HT, Appanah S. 1980. Reproductive biology of some Malaysian dipterocarps. Malaysian Forester 43:132143.

Chien PD, Zuidema PA, Nghia NH. 2008. Conservation prospects for threatened Vietnamese tree species: results from a demographic study. Population Ecology 50:227237

Crawley MJ, Long R. 1995. Alternate bearing, predator satiation and seedling recruitment in Quercus robur L. Journal of Ecology 83:683-696. 
Curran LM, Leighton M. 2000. Vertebrate responses to spatiotemporal variation in seed production of mastfruiting Dipterocarpaceae. Ecological Monograph 70:101-128

Curran LM, Webb CO. 2000. Experimental tests of the spatiotemporal scale of seed predation in mastfruiting Dipterocarpaceae. Ecological Monograph 70:129-148.

Herrera CM, Jordano P, Guitian J. Traveset A. 1998. Annual variability in seed production by woody plants and the masting concept: reassessment of principles and relationship to pollination and seed dispersal. The American Naturalist 152:576-594.

Ichie T, Kenzo T, Kitahashi Y, Koike T, Nakashizuka T. 2005. How does Dryobalanops aromatica supply carbohydrate resource for reproduction in a masting year? Trees-Structure and Function 19:703-710.

Inoue T. 1997. Reproductive phenology of plants and pollination symbiosis. Shinrin-Kagaku 20:14-23 (in Japanese).

Isagi Y, Sugimura K, Sumida A, Ito H. 1997. How does masting happen and synchronize. Journal of Theoretical Biology 187:231-239.

Janzen DH. 1974. Tropical blackwater rivers, animals and mast flowering by the Dipterocarpaceae. Biotropica 6:69-103.

Jinhua W, Rongying L, Er L. 1998. The habit of flowering and fruiting of Scaphium lychnophorum. Journal of Chinese Medicinal Materials 21:487-489 (in Chinese).

Kelly D. 1994. The evolutionary ecology of mast seeding. Trends in Ecology and Evolution 9:465-470.

Kelly D, Hart DE, Allen RB. 2001. Evaluating the windpollination benefits of mast seeding. Ecology 82:117126.

Kelly D, Sullivan JJ. 1997. Quantifying the benefits of mast seeding on predator satiation and wind pollination in Chionochloa pallens (Poaceae). Oikos 78:143-150.

Kochummen KM. 1972. Sterculiaceae. In: Whitmore, T.C. (ed) Tree flora of Malaya vol. 2, Longman, Kuala Lumpur, Malaysia. 353-382.

Koenig WD, Mumme RL, Carmen WJ, Stanback MT. 1994. Acorn production by oaks in central coastal California: variation within and among years. Ecology 75:99-109.

Kohyama T, Suzuki E, Partomohardjo T, Yamada T, Kubo T. 2003. Tree species differentiation in growth, recruitment and allometry in relation to maximum height in a Bornean mixed dipterocarp forest.
Journal of Ecology 91:797-806.

Kon H, Noda T, Terazawa K, Koyama H, Yasaka M. 2005. Evolutionary advantages of mast seeding in Fagus crenata. Journal of Ecology 93:1148-1155.

de Kroon H, Plaisier A, Van Groenendael J, Caswell H. 1986. Elasticity: the relative contribution of demographic parameters to population growth rate. Ecology 67:1427-1431.

Momose K, Yumoto T, Nagamitsu T, Kato M, Nagamasu H, Sakai S, Harrison RD, Itioka T, Hamid AA, Inoue T. 1998. Pollination biology in a lowland dipterocarp forest in Sarawak, Malaysia I: characteristics of the plant-pollinator community in a lowland dipterocarp forest. American Journal of Botany 85:1477-1501.

Naito Y, Kanzaki M, Iwata H, Obayashi K, Lee SL, Muhammad N, Okuda T, Tsumura Y. 2008. Densitydependent selfing and its effects on seed performance in a tropical canopy tree species, Shorea acuminata (Dipterocarpaceae). Forest Ecology and Management 256:375-383.

Nakagawa M, Tanaka K, Nakashizuka T, Ohkubo T, Kato T, Maeda T, Sato K, Miguchi H, Nagamasu H, Ogino K, Teo S, Hamid AA, Lee HS. 2000. Impact of severe drought associated with the 1997-1998 El Niño in a tropical forest in Sarawak. Journal of Tropical Ecology 16:355-367.

van Nieuwstadt MGL, Sheil D. 2005. Separating the effects of severe drought and subsequent fire on tree survival in a lowland dipterocarp rain forest in East Kalimantan, Indonesia. Journal of Ecology 93:191-201.

Norton DA, Kelly D 1988. Mast seeding over 33 years by Dacrydium cupressinum Lamb. (rimu) (Podocarpaceae) in New Zealand: the importance of economies of scale. Functional Ecology 2:399-408.

Numata S, Yasuda M, Okuda T, Kachi N, Noor MSMd. 2003. Temporal and spatial patterns of mass flowerings on the Malay Peninsula. American Journal of Botany 90:1025-1031.

Ropelewski CF, Halpert MS. 1996. Quantifying Southern Oscillation - precipitation relationships. Journal of Climate 9:1043-1059.

Sakai S. 2002. General flowering in lowland mixed dipterocarp forests of Southeast Asia. Biological Journal of the Linnean Society of London 75:233-247.

Sakai SK, Momose T, Yumoto T, Nagamitsu H, Nagamasu A, Hamid A, Nakashizuka T, Inoue, T. 1999. Plant reproductive phenology over four years including an episode of general flowering in a lowland dipterocarp forest, Sarawak, Malaysia. American 
Journal of Botany 86:1414-1436.

Sheil D, Burslem DFRP, Alder D. 1995. The interpretation and misinterpretation of mortality rate measures. Journal of Ecology 93:331-333.

Shibata M, Tanaka H, Iida S, Abe S, Masaki T, Niiyama K, Nakashizuka T. 2002. Synchronized annual seed production by 16 principal tree species in a temperate deciduous forest, Japan. Ecology 83:17271742.

Shibata M, Tanaka H, Nakashizuka T. 1998. Causes and consequences of mast seed production of four co-occurring Carpinus species in Japan. Ecology 79:54-64.

Silva JF, Raventos J, Caswell H, Trevisan MC. 1991. Population responses to fire in a tropical savanna grass, Andropogon semiberbis: a matrix model approach. Journal of Ecology 79:345-356.

Silvertown JW. 1980. The evolutionary ecology of mast seeding in trees. Biological Journal of Linnean Society 14:235-250.

Silvertown J, Franco M, McConway, K. 1992. A demographic interpretation of Grime's triangle. Functional Ecology 6:130-136.

Silvertown J, Franco M, Pisanty I, Mendoza A. 1993. Comparative plant demography -relative importance of life-cycle components to the finite rate of increase in woody and herbaceous perennials. Journal of Ecology 81:465-476.

Simbolon H, Yamada T, Suzuki E. 2000. Elateriospermum tapos Blume (Euphorbiaceae) in West Kalimantan: Spatial distribution, survival and growth in a mixed dipterocarp forest. Tropics 9:91-102.

Smith CC, Hamrick JL, Kramer CL. 1990. The advantage of mast years for wind pollination. The American Naturalist 136:154-166.

Sork VL. 1993. Evolutionary ecology of mast-seeding in temperate and tropical oaks (Quercus spp.). Vegetatio 107/108:133-147.

Sork VL, Bramble J, Sexton O. 1993. Ecology of mastfruiting in three species of North American deciduous oaks. Ecology 74:528-541.

Sun IF, Chen YY, Hubbell SP, Wright SJ, Noor N. 2007. Seed predation during general flowering events of varying magnitude in a Malaysian rain forest. Journal of Ecology 95:818-827.

Tuljapurkar S, Horvitz CC, Pascarella JB. 2003. The many growth rates and elasticities of populations in random environments. The American Naturalist 162:489-502.

Visser MD, Jongejans E, van Breugel M, Zuidema PA,
Chen YY, Kassim AR, de Kroon H. 2011. Strict mast fruiting for a tropical dipterocarp tree: a demographic cost-benefit analysis of delayed reproduction and seed predation. Journal of Ecology 99:1033-1044.

Walsh RPD. 1996. Drought frequency changes in Sabah and adjacent parts of northern Borneo since the late nineteenth century and possible implications for tropical rain forest dynamics. Journal of Tropical Ecology 12:385-407.

Walsh RPD, Newbery DM. 1999. The ecoclimatology of Danum, Sabah, in the context of the world's rainforest regions, with particular reference to dry periods and their impact. Philosophical Transactions of the Royal Society B 354:1869-1883.

Yamada T, Suzuki E. 1996. Ontogenetic change in leaf shape and crown form of a tropical tree, Scaphium macropodum (Sterculiaceae) in Borneo. Journal of Plant Research 109:219-225.

Yamada T, Suzuki E. 1997. Changes in spatial distribution during the life history of a tropical tree, Scaphium macropodum (Sterculiaceae) in Borneo. Journal of Plant Research 110:179-186.

Yamada T, Zuidema PA, Itoh A, Yamakura T, Ohkubo T, Kanzaki M, Tan S, Ashton PS. 2007. Strong habitat specificity of a tropical rain forest tree does not imply large differences in population dynamics across habitats. Journal of Ecology 95:332-342.

Yasuda M, Matsumoto J, Osada N, Ichikawa S, Kachi N, Tani M, Okuda T, Furukawa A, Nik AR, Manokaran N. 1999. The mechanism of general flowering in Dipterocarpaceae in the Malay Peninsula. Journal of Tropical Ecology 15:437-449.

Zuidema PA, Boot RGA. 2002. Demography of the Brazil nut tree (Bertholletia excelsa) in the Bolivian Amazon: impact of seed extraction on recruitment and population dynamics. Journal of Tropical Ecology 18:1-31.

Zuidema PA, Yamada T, During HD, Itoh A, Yamakura T, Ohkubo T, Kanzaki M, Tan S, Ashton PS. 2010. Recruitment subsidies support tree subpopulations in non-preferred tropical forest habitats. Journal of Ecology 98:636-644.

The following material is available for this article:

Table S1. Matrix used for this study.

Received $31^{\text {st }}$ Jan. 2012 Accepted 26 ${ }^{\text {th }}$ June 2012 


\section{APPENDIX}

Table S1. The $15 \times 15$ matrix used in this study.

\begin{tabular}{|c|c|c|c|c|c|c|c|c|c|c|c|c|c|c|c|}
\hline & 1 & 2 & 3 & 4 & 5 & 6 & 7 & 8 & 9 & 10 & 11 & 12 & 13 & 14 & 15 \\
\hline 1 & 0 & 0 & 0 & 0 & 0 & 0 & 0 & 0 & 383.4 & 1150.3 & 1917.1 & 2684 & 3450.8 & 4217.7 & 4601.1 \\
\hline 2 & 0.081 & 0.405 & 0 & 0 & 0 & 0 & 0 & 0 & 0 & 0 & 0 & 0 & 0 & 0 & 0 \\
\hline 3 & 0 & 0.058 & 0.917 & 0 & 0 & 0 & 0 & 0 & 0 & 0 & 0 & 0 & 0 & 0 & 0 \\
\hline 4 & 0 & 0 & 0.052 & 0.955 & 0 & 0 & 0 & 0 & 0 & 0 & 0 & 0 & 0 & 0 & 0 \\
\hline 5 & 0 & 0 & 0 & 0.03 & 0.977 & 0 & 0 & 0 & 0 & 0 & 0 & 0 & 0 & 0 & 0 \\
\hline 6 & 0 & 0 & 0 & 0 & 0.008 & 0.987 & 0 & 0 & 0 & 0 & 0 & 0 & 0 & 0 & 0 \\
\hline 7 & 0 & 0 & 0 & 0 & 0 & 0.003 & 0.974 & 0 & 0 & 0 & 0 & 0 & 0 & 0 & 0 \\
\hline 8 & 0 & 0 & 0 & 0 & 0 & 0 & 0.016 & 0.948 & 0 & 0 & 0 & 0 & 0 & 0 & 0 \\
\hline 9 & 0 & 0 & 0 & 0 & 0 & 0 & 0 & 0.042 & 0.92 & 0 & 0 & 0 & 0 & 0 & 0 \\
\hline 10 & 0 & 0 & 0 & 0 & 0 & 0 & 0 & 0 & 0.07 & 0.908 & 0 & 0 & 0 & 0 & 0 \\
\hline 11 & 0 & 0 & 0 & 0 & 0 & 0 & 0 & 0 & 0 & 0.082 & 0.918 & 0 & 0 & 0 & 0 \\
\hline 12 & 0 & 0 & 0 & 0 & 0 & 0 & 0 & 0 & 0 & 0 & 0.072 & 0.936 & 0 & 0 & 0 \\
\hline 13 & 0 & 0 & 0 & 0 & 0 & 0 & 0 & 0 & 0 & 0 & 0 & 0.054 & 0.954 & 0 & 0 \\
\hline 14 & 0 & 0 & 0 & 0 & 0 & 0 & 0 & 0 & 0 & 0 & 0 & 0 & 0.036 & 0.966 & 0 \\
\hline 15 & 0 & 0 & 0 & 0 & 0 & 0 & 0 & 0 & 0 & 0 & 0 & 0 & 0 & 0.024 & 0.99 \\
\hline
\end{tabular}

